\title{
Phase 2 clinical trial of sunitinib as adjunctive treatment in patients with advanced differentiated thyroid cancer
}

\author{
Athanasios Bikas ${ }^{1,2}$, Priya Kundra ${ }^{1}$, Sameer Desale ${ }^{2}$, Mihriye Mete ${ }^{2}$, \\ Kaitlyn O'Keefe ${ }^{2,+}$, Brandon G Clark ${ }^{2}$, Lynette Wray ${ }^{2}$, Rahul Gandhi' ${ }^{2}$, \\ Christina Barett ${ }^{2}$, James S Jelinek ${ }^{3}$, Jason A Wexler ${ }^{1}$, Leonard Wartofsky ${ }^{1}$ and \\ Kenneth D Burman ${ }^{1}$ \\ ${ }^{1}$ Division of Endocrinology, Department of Medicine, MedStar Washington Hospital Center, ${ }^{2}$ MedStar Health \\ Research Institute and ${ }^{3}$ Department of Radiology, MedStar Washington Hospital Center, 110 Irving Street \\ Northwest, Washington, District of Columbia 20010, USA \\ ${ }^{\dagger}$ (K O'Keefe is now at 3804 Westbury Court, Apt 6, Fayetteville, North Carolina 28314, USA)
}

\author{
Correspondence \\ should be addressed \\ to A Bikas \\ Email \\ Athanasios.Bikas@ \\ medstar.net
}

\begin{abstract}
Objective: Our objective was to evaluate the efficacy and safety of sunitinib following at least one course of radioactive iodine treatment in patients with advanced differentiated thyroid cancer (DTC). The study endpoints included best response rate (including best objective response rate) and progression-free survival (PFS) per Response Evaluation Criteria in Solid Tumors (RECIST) 1.1, measurement of serum thyroglobulin (Tg), and toxicity evaluation.

Design and methods: This was a single center, nonrandomized, open-label, phase 2 clinical trial. In total, 23 patients were enrolled and were treated with a starting daily, oral dose of $37.5 \mathrm{mg}$ sunitinib. Patients were evaluated with imaging, laboratory tests, and physical examination periodically per protocol.

Results: The mean best response was a decrease of $17.2 \%$ (s.D. 22.8) in tumor sum from baseline. Six (26\%) patients achieved a partial response (PR), and $13(57 \%)$ had stable disease (SD) for a clinical benefit rate (PR + SD) of $83 \%$. The overall median PFS was 241 days (interquartile limits, 114-518). No statistically significant difference was observed between the medians of the baseline and post-treatment Tg values $(P=0.24)$. The most common adverse events included grades 1 and 2 decreases in blood cell counts (especially leukocytes), diarrhea, fatigue, hand-foot skin reaction, nausea, musculoskeletal pain, and hypertension.

Conclusions: These data demonstrate that sunitinib exhibits significant anti-tumor activity in patients with advanced DTC. Since sunitinib was relatively well-tolerated, there is the potential for clinical benefit in these patients, and further investigation of this agent is warranted.
\end{abstract}

\section{Introduction}

Differentiated thyroid cancer (DTC) is the most common endocrine malignancy, with 62450 new cases expected to be diagnosed in 2015 in the USA (1). DTC is classified histologically as papillary, follicular (including Hürthle cell), or poorly differentiated (2). In general, patients with DTC have an excellent prognosis and 10-year survival rate ranging between 80 and 95\% $(3,4)$. DTC patients with distant metastases represent a very heterogeneous group with 10-year survival rate ranging from 26 to $70 \%(5,6)$, but generally, the prognosis is worse with most authors reporting a 10-year survival rate of $\sim 40 \%$ (7). Development of recurrent disease significantly worsens prognosis.

Published by Bioscientifica Ltd. 
DTC recurrence rate has been reported to be $1.4-23 \%(8,9)$ and depends on the initial and ongoing risk stratification (10). The mortality of patients with a recurrence has been shown to be as high as $38-69 \%(11,12)$. Furthermore, $2-5 \%$ of patients with initially differentiated tumors can develop refractoriness to radioiodine and iodine-131 $\left({ }^{131} \mathrm{I}\right)$-negative metastases. Loss of differentiation is generally associated with a poor prognosis (13). Patients with ${ }^{131}$ I-positive metastases have demonstrated a $60 \%$ 10 -year survival in comparison to $10 \%$ for patients with ${ }^{131}$ I-negative metastases (14). It is apparent that new therapeutic strategies are needed in order to improve the prognosis in patients with aggressive disease.

Tyrosine kinase inhibitors (TKIs) have emerged as a promising therapeutic strategy, targeting a variety of tyrosine kinases based on the molecular biology of tumors. Thyroid tumors are highly vascular, and overexpression of the vascular endothelial growth factor receptor (VEGFR) has been reported in DTC (15). Likewise, overexpression of the platelet-derived growth factor receptor (PDGFR) is well-established in thyroid cancer, and PDGFR-a has been associated with lymph node metastases in papillary thyroid cancer (PTC) (16). The RET/PTC rearrangements are one of the most common genetic alteration described in PTC, and in the USA, the prevalence of the mutation has been reported to be $11-43 \%(17,18)$. As a result, a TKI that would target those kinases could potentially be effective in the treatment of DTC.

Sunitinib is a small molecule multi-TKI. It targets VEGFR, PDGFR, RET, the stem cell factor receptor KIT, and the FMS-like tyrosine kinase 3 ligand receptor (19). Sunitinib is approved from the US Food and Drug Administration (FDA) for the treatment of advanced renal cell carcinoma, gastrointestinal (GI) stromal tumor after disease progression on or intolerance to imatinib, and progressive, well-differentiated pancreatic neuroendocrine tumors in patients with unresectable locally advanced or metastatic disease.

Kim et al. (20) studied the effect of sunitinib on thyroid oncogenic RET/PTC kinases, which are known to mediate thyroid cancer progression. By using an in vitro kinase assay, they discovered that sunitinib inhibited the phosphorylation of the synthetic tyrosine kinase substrate peptide E4Y by RET/PTC3 in a dose-dependent manner. Sunitinib was, therefore, considered to be a potentially highly effective TKI of the RET/PTC oncogenic kinase. These data, along with the effect of sunitinib on VEGFR and PDGFR, prompted us to initiate a single-center, phase 2 clinical trial in order to evaluate the efficacy and safety of sunitinib in patients with advanced DTC.

\section{Patients and methods}

\section{Patients}

Eligible patients were $\geq 18$ years old with histologically confirmed DTC (e.g. PTC, follicular thyroid cancer, or poorly DTC) that had evidence of metastatic, residual, recurrent, or progressive disease (PD). All patients during enrollment demonstrated distant metastasis being classified as either stage 2 (younger than 45 years old) or stage $4 \mathrm{C}$ by American Joint Committee on Cancer. They all had been previously treated with at least one course of radioactive iodine (RAI) therapy for curative purposes, but their disease had progressed post-RAI, and curative measures were no longer effective. All patients had at least one measurable site of disease as defined by the Response Evaluation Criteria in Solid Tumors version 1.1 (RECIST 1.1). RECIST 1.1 was published in 2009 and quickly became the standard of care for the evaluation of solid tumors. For that reason (and because our study was initiated in 2008), we repeated the response grids (of all patients that had been evaluated with RECIST 1.0) using RECIST 1.1. In order to be included in the study, patients had to have an Eastern Cooperative Oncology Group (ECOG) performance status $\leq 2$, life expectancy more than 3 months, serum aspartate transaminase (AST) and serum alanine transaminase (ALT) $\leq 2.5 \times$ upper limit of normal (ULN), or AST and ALT $\leq 5 \times$ ULN if liver function abnormalities are due to underlying malignancy, total serum bilirubin $\leq 1.5 \times$ ULN, serum albumin $\geq 3.0 \mathrm{~g} / \mathrm{dl}$, absolute neutrophil count $\geq 1500 / \mu \mathrm{l}$, platelets $\geq 100000 / \mu \mathrm{l}$, hemoglobin $\geq 9.0 \mathrm{~g} / \mathrm{dl}$, and serum creatinine $\leq 1.5 \times$ ULN. Premenopausal women were required to have a negative pregnancy test, while all patients with childbearing potential agreed to use effective contraception.

Patients were excluded if they had received prior systemic chemotherapy or targeted therapy within 3 months prior to sunitinib initiation, prior external beam radiation therapy (EBRT) to the target lesions, and/or prior treatment with sunitinib. Patients were also excluded if they had history of any other carcinomas within the last 5 years (except for cured basal cell carcinoma of the skin and cured in situ cervical cancer), serious uncontrolled concomitant disease that could compromise study participation, active human immunodeficiency virus infection, lack of physical integrity of the upper GI tract or malabsorption syndrome, and/or the inability to take oral medication. All patients provided written informed consent before enrollment into the trial. The study protocol was approved by the Local Institutional Review Board. 


\section{Study design}

This was a single center, nonrandomized, open-label, and phase 2 clinical trial for preliminary evaluation of the efficacy and safety of sunitinib following at least one course of RAI treatment in patients with DTC (ClinicalTrials.gov identification number (NCT: 00668811)). Sunitinib was administered orally at $37.5 \mathrm{mg}$ once daily. A treatment cycle was considered 28 days. Patients experiencing doselimiting toxicity had their dose decreased to a tolerable level before trying to readjust (details on the management of the sunitinib dose post-toxicity are provided in Supplementary Tables 1, 2 and 3, see section on supplementary data given at the end of this article). Screening evaluation was performed at baseline with a physical examination, medical history, electrocardiogram (EKG), and laboratory evaluations including thyroid testing, urinalysis, and imaging modalities including neck ultrasound, magnetic resonance imaging (MRI), computed tomography (CT), positron emission tomography (PET)-diagnostic CT, and echocardiography. During the first four cycles, patients were evaluated at the end of each cycle. After that time period, patients were evaluated once every $4-8$ weeks/ protocol, alternating physical exam, medical history, and laboratory testing, with imaging modalities. All at each visit drug compliance and accountability, adverse events, concomitant medications, and therapies were assessed.

\section{Study endpoints}

The primary endpoints of this study were best response rate (including best objective response rate) and progression-free survival (PFS). Secondary endpoints included overall survival (OS) and serum thyroglobulin (Tg) levels of patients that were on sunitinib. The study endpoints of best response, stable disease (SD), or PD were measured based on the findings on CT or MRI using RECIST 1.1. All responses and progressions were confirmed by a single, senior, study-designated radiologist blinded to clinical and laboratory data. Finally, another secondary endpoint was to assess the type, incidence, severity, timing, seriousness, and relatedness of adverse events. Adverse events were graded with the use of Common Terminology Criteria for Adverse Events (version 3).

\section{Statistical analysis}

The sample size was calculated according to Simon's phase 2 optimal two-stage study. For power calculation, we set the uninteresting level $(\mathrm{PO})=10 \%$, desirable target level $(\mathrm{P} 1)=30 \%$ with $\alpha=0.05$, and power $=90 \%$.
Sunitinib would be ineffective or uninteresting if the true response (partial response (PR) + complete response (CR)) probability was lower than $10 \%$, and the regimen would be worthy of further study if the true response probability were $\geq 30 \%$. The required sample size for stage 1 was 18 and 17 for an optional stage 2, for a total sample size of 35. If we observed more than two successes (objective responses, PR, and/or CR) among the first 18 patients, we would proceed to the second stage. Our final recruitment reached 23 patients. Estimates of PFS (time from starting study drug to progression or death, whichever occurred first) and OS (time from starting study drug to death from whatever reason) with associated interquartile limits were obtained using the Kaplan-Meier method. All enrolled patients who received at least 1 day of treatment were included in this intent-to-treat analysis.

\section{Results}

\section{Baseline characteristics}

Baseline patient characteristics are presented in Table 1 . In total, 74\% (17) of the patients enrolled were male, while

Table 1 Patients' baseline characteristics.

\begin{tabular}{|c|c|}
\hline Baseline characteristics & Values \\
\hline$n$ & $23(100 \%)$ \\
\hline \multicolumn{2}{|l|}{ Gender } \\
\hline Female & $6(26 \%)$ \\
\hline Male & $17(74 \%)$ \\
\hline \multicolumn{2}{|l|}{ Age at enrolment } \\
\hline Median & 61 \\
\hline Range & $25-80$ \\
\hline \multicolumn{2}{|l|}{ Histology } \\
\hline Papillary & $16(70 \%)$ \\
\hline Follicular (with Hürthle cell) & $6(26 \%)$ \\
\hline Poorly differentiated & $1(4 \%)$ \\
\hline \multicolumn{2}{|l|}{ Prior surgery } \\
\hline Total thyroidectomy & $23(100 \%)$ \\
\hline Prior ${ }^{131}$ I treatment & $23(100 \%)$ \\
\hline \multicolumn{2}{|c|}{ Number of ${ }^{131}$ I therapies per patient } \\
\hline Median & 3 \\
\hline Range & $1-7$ \\
\hline \multicolumn{2}{|c|}{ Cumulative dosage of ${ }^{131} \mid$ received $(\mathrm{mCi})$} \\
\hline Mean \pm s.D. & $600.2 \pm 274.8$ \\
\hline Range & $150-1148$ \\
\hline \multicolumn{2}{|l|}{ Prior EBRT } \\
\hline Yes & $14(61 \%)$ \\
\hline No & $9(39 \%)$ \\
\hline \multicolumn{2}{|l|}{ Distant metastasis at enrolment } \\
\hline Distant metastasis & $23(100 \%)$ \\
\hline Lung & $21(91 \%)$ \\
\hline Bone & $10(43 \%)$ \\
\hline Both lung and bone & $8(35 \%)$ \\
\hline \multicolumn{2}{|c|}{ Baseline ECOG performance status } \\
\hline 0 & $17(74 \%)$ \\
\hline 1 & $6(26 \%)$ \\
\hline
\end{tabular}




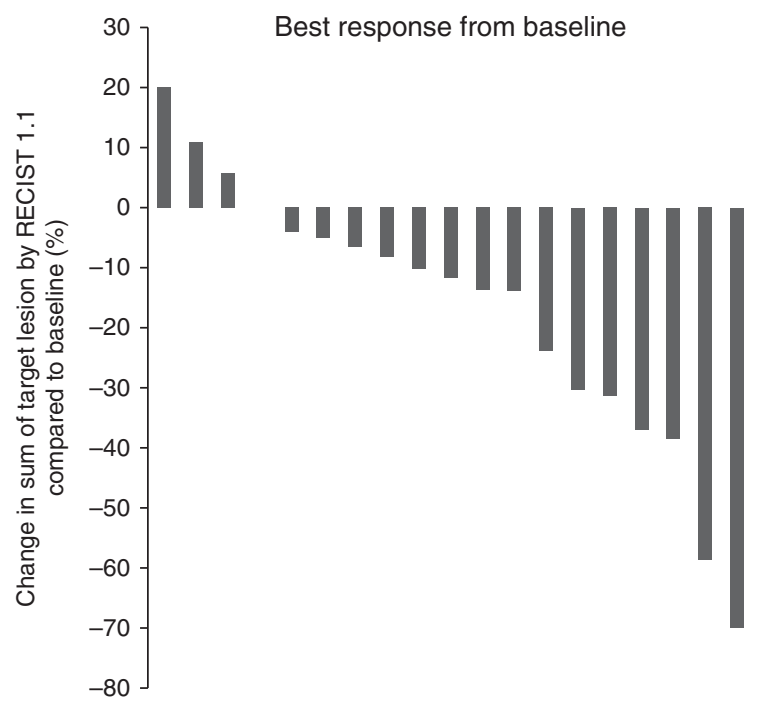

\section{Figure 1}

Waterfall plot depicting the best overall change from baseline in target lesion measurements of all patients who had a clinical benefit from sunitinib treatment (PR+SD). Radiographic measurements of target lesions over the course of the study were compared with the baseline measurements, and the best change is depicted in this figure. PR, partial response; SD, stable disease; RECIST 1.1, Response Evaluation Criteria in Solid Tumors version 1.1.

the median age of the patients at enrollment in the study was 61 years old. Lung metastasis was documented in 91\% $(21 / 23)$ and bone metastasis in $43 \%(10 / 23)$ of the patients at baseline. All patients, except for one, had disease that had progressed in the last 12 months before enrolling to the study, per the evaluation of their latest scans. The one patient that did not demonstrate anatomically PD had escalating Tg levels and could not be administered RAI, as he suffered from serious side effects from prior administrations. This patient had bilateral neck disease, lung metastasis with positive ${ }^{18}$ FDG-PET uptake (but no CT scan correlate), and bone metastases evidenced by sclerotic changes in the diagnostic CT scan in sternum and right superior pubic ramus. So, the treating team decided that this patient had PD that could not be detected at that time and decided that it would be to the patient's benefit to be enrolled to the current clinical trial. As per protocol, all patients had at least had one previous RAI treatment. The median number of RAI treatments was 3 , and the mean cumulative dosage of RAI was 600.2 mCi. Previously, 13 (61\%) had EBRT. No patient had been previously treated with a TKI.

\section{Treatment administration}

The first patient was enrolled in September 2008, and the study officially closed enrollment in October 2014. All data analysis was performed in February 2015. At the time of data analysis, all 23 patients were off the study. In total, $5 / 23$ (22\%) completed treatment, 9/23 (39\%) came off the study due to PD, $1 / 23$ (4\%) came off the study due to a second primary carcinoma (ductal carcinoma in situ in breast), 3/23 (13\%) came off the study due to side effects, $2 / 23$ (8\%) withdrew from the study, $1 / 23$ (4\%) came off the study in order to receive additional external radiation therapy to metastatic disease in the spine, 1/23 (4\%) did not have the tumors evaluated due to severe toxicities leading to hospitalization, and 1/23 (4\%) died of disease before the evaluation of the first month took place. The median duration of sunitinib treatment was nine cycles (range 1-24 cycles).

\section{Efficacy}

In total, 20 patients were assessable for response, but all 23 patients were included in this intent-to-treat analysis. The best response rate was calculated and is presented as a percentage to the sum of the longest diameters of lesions that were documented at enrollment. The response rates ranged from $\mathrm{PD}$ to a decrease in the sum of the target lesions by $69.92 \%$ by the RECIST 1.1 . No patient achieved a CR (disappearance of all target lesions per RECIST 1.1) during the treatment with sunitinib. In total, 6/23 (26\%) had a PR (decrease in sum of the longest diameter measurements $\geq 30 \% /$ RECIST 1.1 ). So, the objective response rate for our study was $26 \%$. In total, $13 / 23$ $(57 \%)$ had SD (change in the sum of the longest diameter measurements between -30 and $+20 \%$ /RECIST 1.1 ) as

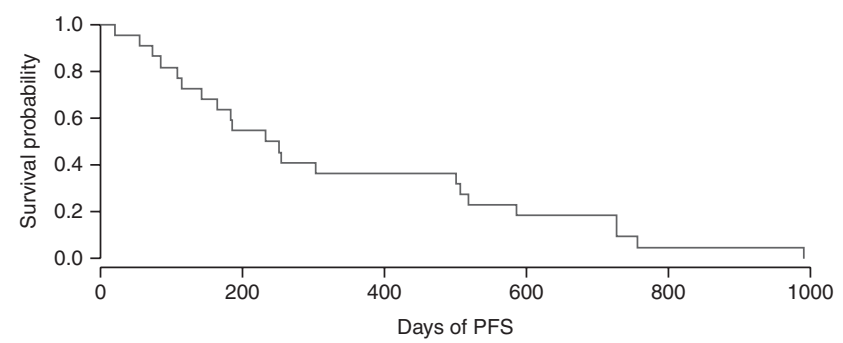

\section{Figure 2}

Kaplan-Meier curve for the PFS of patients. Median PFS was 241 days with interquartile limits of $114-518$. PFS, progressionfree survival. 


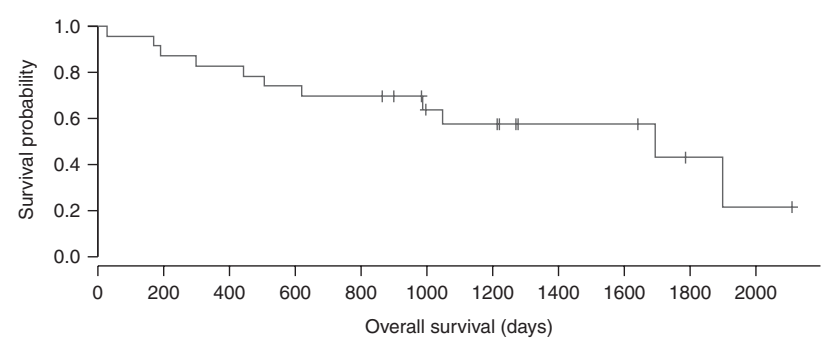

Figure 3

Kaplan-Meier curve for the OS of patients. The median OS, as calculated in February 2015, was 1694 days with interquartile limits of 505-1898 days. OS, overall survival.

their best response during treatment with sunitinib. In total, 1/23 (4\%) had PD (increase in sum of the longest diameter measurements $\geq 20 \%$ or appearance of new lesion per RECIST 1.1). Therefore, the clinical benefit ratio of our study $(\mathrm{PR}+\mathrm{SD})$ was $83 \%$. The best responses of all patients who had a clinical benefit from the study are depicted in the waterfall plot in Fig. 1. The mean best response change from baseline was $-17.2 \%$ (s.D. $=22.8 \%$ ). The median PFS in our cohort of patients was 241 days with interquartile limits of 114-518. The median OS, as calculated by February 2015, was 1694 days with interquartile limits of 505-1898 days. Figures 2 and 3 show the Kaplan-Meier curves for all 23 patients for PFS and OS respectively.

\section{Biochemical response}

In total, 18 (78\%) patients had evaluable serum $\mathrm{Tg}$ values at enrollment. Three (13\%) were $\mathrm{Tg}$ antibodies positive, while $2(9 \%)$ did not have a recent numerical value documented in their chart. During the first 2 months of treatment (with 17 patients available for evaluation), a decrease in the mean serum Tg values was noted. During the first 6 months of sunitinib (with 12 patients available for analysis), the decreasing trend persisted, but at the end of treatment (EOT) (with 18 patients evaluable), the serum Tg levels had increased compared to the 6 months levels, and no statistically significant difference was observed between the enrollment and the end-of-treatment $\mathrm{Tg}$ values $(P=0.24)$. In Table 2 , the percent change from baseline is presented for all evaluable patients at 2-6 months from the beginning of treatment and at the EOT. At 2 months, $42 \%$ of patients had a decrease at their serum Tg levels by more than $50 \%$, while at 6 months, $50 \%$ of evaluable patients recorded the same level of decrease.

\section{Adverse events}

Sunitinib was generally well-tolerated. In total, 3/23 (13\%) discontinued treatment as a result of side effects $(n=1$ due to neutropenia and $n=2$ due to hypertension). In total, $1 / 23(4 \%)$ did not have the tumors evaluated due to severe toxicities leading to hospitalization (due to diarrhea, volume depletion, and hyponatremia). In all, 6/23 patients (26\%) required a dose reduction from the initial 37.5-25 mg/once per day due to adverse events ( $n=3$ due to hand-foot syndrome; $n=1$ due to diarrhea; $n=1$ due to hypertension; and $n=1$ due to GI distress, anorexia, and fatigue).

All observed adverse events are listed in Table 3. Treatment-related adverse events were predominantly grade 1 or 2 . The most common were leukopenia (83\%), thrombocytopenia (57\%), fatigue (52\%), diarrhea (52\%), musculoskeletal pain (43\%), and hand-foot syndrome (39\%). Grade 3 adverse events were more infrequent, with the most commonly encountered being leukopenia (13\%), hypertension (13\%), hand-foot syndrome (9\%), and anorexia (9\%). All the rest grade 3 events did not exceed $4 \%(n=1)$ of the patients. No grade 4 or 5 adverse events were documented in the study. In total, 7/23 (30\%) patients needed a dose adjustment in thyroid hormone replacement therapy due to inappropriately elevated thyroid-stimulating hormone during sunitinib treatment.

\section{Discussion}

The unraveling of the molecular basis and the pathobiology of thyroid carcinomas has allowed the development of multi-target drug therapies that have revolutionized the way DTC is addressed. TKIs have gained promise in an effort to control DTC. The role of VEGFR, PDGFR, and RET tyrosine kinases is well-established in the pathogenesis of advanced stage DTC. We conducted a phase 2 clinical trial examining the response of patients with advanced, progressive DTC to sunitinib, an oral small molecule multi-kinase inhibitor. The median PFS in our

Table 2 Tg response to sunitinib.

\begin{tabular}{|c|c|c|c|}
\hline & 2 months & 6 months & EOT \\
\hline Evaluable patients & $17(100 \%)$ & $12(100 \%)$ & $18(100 \%)$ \\
\hline \multicolumn{4}{|l|}{ Tg response } \\
\hline$\geq 75 \%$ decrease & $3(18 \%)$ & $3(25 \%)$ & $2(11 \%)$ \\
\hline $50-74 \%$ decrease & $4(24 \%)$ & $3(25 \%)$ & $4(22 \%)$ \\
\hline $25-49 \%$ decrease & $4(24 \%)$ & $2(17 \%)$ & $3(17 \%)$ \\
\hline $0-24 \%$ decrease & $2(12 \%)$ & $2(17 \%)$ & $3(17 \%)$ \\
\hline$>0 \%$ increase & $4(24 \%)$ & $2(17 \%)$ & $6(33 \%)$ \\
\hline
\end{tabular}


Table 3 Treatment-related adverse events.

\begin{tabular}{|c|c|c|c|c|}
\hline \multirow[b]{2}{*}{ Adverse events } & \multicolumn{2}{|c|}{ Grades 1-2 } & \multicolumn{2}{|c|}{ Grade 3} \\
\hline & $\begin{array}{l}\text { No. of } \\
\text { patients }\end{array}$ & $\begin{array}{l}\text { Percentage } \\
\text { of patients }\end{array}$ & $\begin{array}{l}\text { No. of } \\
\text { patients }\end{array}$ & $\begin{array}{l}\text { Percentage } \\
\text { of patients }\end{array}$ \\
\hline Allergic reaction & - & - & 1 & 4 \\
\hline Auditory/ear & 1 & 4 & - & - \\
\hline \multicolumn{5}{|l|}{ Blood/bone marrow } \\
\hline Anemia & 11 & 48 & - & - \\
\hline Leukopenia & 19 & 83 & 3 & 13 \\
\hline Neutropenia & 15 & 65 & 1 & 4 \\
\hline Lymphopenia & 5 & 22 & 1 & 4 \\
\hline Thrombocytopenia & 13 & 57 & 1 & 4 \\
\hline \multicolumn{5}{|l|}{ Cardiac } \\
\hline $\begin{array}{l}\text { Supraventricular } \\
\text { arrhythmia }\end{array}$ & 2 & 9 & - & - \\
\hline Hypertension & 6 & 26 & 3 & 13 \\
\hline \multicolumn{5}{|l|}{ Constitutional } \\
\hline Fatigue & 12 & 52 & 1 & 4 \\
\hline Fever & 3 & 13 & - & - \\
\hline Insomnia & 5 & 22 & - & - \\
\hline Chills & 3 & 13 & - & - \\
\hline Weight loss & 8 & 35 & - & - \\
\hline \multicolumn{5}{|l|}{ Dermatology } \\
\hline Acne & 2 & 9 & - & - \\
\hline Alopecia & 2 & 9 & - & - \\
\hline Bruising & 2 & 9 & - & - \\
\hline Dry skin & 1 & 4 & - & - \\
\hline $\begin{array}{l}\text { Hand-foot } \\
\text { syndrome }\end{array}$ & 9 & 39 & 2 & 9 \\
\hline Hyperpigmentation & 1 & 4 & - & - \\
\hline Hypopigmentation & 3 & 13 & - & - \\
\hline Rash & 4 & 17 & - & - \\
\hline Ulceration & 1 & 4 & - & - \\
\hline \multicolumn{5}{|l|}{ Gastrointestinal } \\
\hline Anorexia & 7 & 30 & 2 & 9 \\
\hline Constipation & 7 & 30 & - & - \\
\hline Diarrhea & 12 & 52 & 1 & 4 \\
\hline Dry mouth & 1 & 4 & - & - \\
\hline Dysphagia & 2 & 9 & - & - \\
\hline Flatulence & 2 & 9 & - & - \\
\hline Heartburn & 4 & 17 & - & - \\
\hline Hemorrhoids & 3 & 13 & - & - \\
\hline Mucositis & 5 & 22 & 1 & 4 \\
\hline Nausea & 9 & 39 & 1 & 4 \\
\hline Taste alteration & 9 & 39 & - & - \\
\hline Vomiting & 8 & 35 & 1 & 4 \\
\hline \multicolumn{5}{|l|}{ Bleeding } \\
\hline Hematoma & 2 & 9 & - & - \\
\hline Petechiae & 1 & 4 & - & - \\
\hline Hemorrage, Gl & 4 & 17 & 1 & 4 \\
\hline \multicolumn{5}{|l|}{ Infection } \\
\hline Infection & 4 & 17 & - & - \\
\hline Edema & 2 & 9 & 1 & 4 \\
\hline \multicolumn{5}{|l|}{ Metabolic } \\
\hline $\begin{array}{l}\text { Increased alkaline } \\
\text { phosphate }\end{array}$ & 4 & 17 & - & - \\
\hline Increased ALT & 11 & 48 & - & - \\
\hline Increased AST & 11 & 48 & - & - \\
\hline Increased creatinine & 10 & 43 & - & - \\
\hline Hyperglycemia & 11 & 48 & - & - \\
\hline Hypoalbuminemia & 7 & 30 & - & - \\
\hline Hypocalcemia & 10 & 43 & - & - \\
\hline Hypoglycemia & 3 & 13 & 1 & 4 \\
\hline
\end{tabular}

Table 3 Continued

\begin{tabular}{|c|c|c|c|c|}
\hline \multirow[b]{2}{*}{ Adverse events } & \multicolumn{2}{|c|}{ Grades 1-2 } & \multicolumn{2}{|c|}{ Grade 3} \\
\hline & $\begin{array}{l}\text { No. of } \\
\text { patients }\end{array}$ & $\begin{array}{l}\text { Percentage } \\
\text { of patients }\end{array}$ & $\begin{array}{l}\text { No. of } \\
\text { patients }\end{array}$ & $\begin{array}{l}\text { Percentage } \\
\text { of patients }\end{array}$ \\
\hline Hypokalemia & 4 & 17 & - & - \\
\hline Hypomagnesemia & 1 & 4 & - & - \\
\hline Hyponatremia & 6 & 26 & 1 & 4 \\
\hline Lipase & - & - & 1 & 4 \\
\hline Proteinuria & 5 & 22 & - & - \\
\hline \multicolumn{5}{|l|}{ Musculoskeletal } \\
\hline $\begin{array}{l}\text { Extremity - upper } \\
\text { (function) }\end{array}$ & 1 & 4 & 1 & 4 \\
\hline Muscle weakness & 2 & 9 & 1 & 4 \\
\hline \multicolumn{5}{|l|}{ Neurology } \\
\hline Dizziness & 1 & 4 & - & - \\
\hline $\begin{array}{l}\text { Memory } \\
\text { impairment }\end{array}$ & 1 & 4 & - & - \\
\hline \multicolumn{5}{|l|}{ Neuropathy } \\
\hline Cranial & 1 & 4 & 1 & 4 \\
\hline Sensory & 2 & 9 & - & - \\
\hline Syncope & 1 & 4 & - & - \\
\hline Mood alteration & 1 & 4 & - & - \\
\hline \multicolumn{5}{|l|}{ Ocular } \\
\hline Diplopia & 1 & 4 & - & - \\
\hline Flashing lights & 1 & 4 & - & - \\
\hline \multicolumn{5}{|l|}{ Pain } \\
\hline $\mathrm{Gl}$ & 6 & 26 & - & - \\
\hline General & 5 & 22 & - & - \\
\hline Musculoskeletal & 10 & 43 & - & - \\
\hline Neurology & 6 & 26 & 1 & 4 \\
\hline Pulmonary & 4 & 17 & - & - \\
\hline \multicolumn{5}{|l|}{ Pulmonary } \\
\hline Cough & 8 & 35 & - & - \\
\hline Dyspnea & 8 & 35 & - & - \\
\hline Nasal reaction & 2 & 9 & - & - \\
\hline Voice change & 2 & 9 & - & - \\
\hline \multicolumn{5}{|l|}{ Renal } \\
\hline Urine color change & 1 & 4 & - & - \\
\hline Urinary frequency & 2 & 9 & - & - \\
\hline \multicolumn{5}{|l|}{ Vascular } \\
\hline Phlebitis & 1 & 4 & - & - \\
\hline Thrombosis & - & - & 1 & 4 \\
\hline
\end{tabular}

study was 241 days, while the median OS was 1694 days. The clinical benefit ratio $(\mathrm{PR}+\mathrm{SD})$ was $83 \%$, and the mean best response change from baseline was $-17.2 \%$ (s.D. $=$ $22.8 \%)$.

Our clinical trial is, to the best of our knowledge, the first phase 2 clinical trial that has examined the effect of sunitinib solely on DTC, ensuring a homogeneous study population. Two phase 1 clinical trials reported a PR in two patients with thyroid cancer (one patient in each study) after treatment with sunitinib $(21,22)$. Several groups have initiated phase 2 clinical trials of sunitinib in thyroid cancer. Carr et al. (23) included 35 patients in their study (33 evaluable), 28 of whom had DTC and seven had medullary thyroid cancer (MTC). Despite the obvious limitation of not reporting the results separately for DTC 
and MTC, the responses in their cohort of patients were: CR in $3 \%$, PR in $28 \%$, SD in $46 \%$, and PD in $17 \%$ of the patients. Two independent groups reported preliminary results of their phase 2 clinical trials in form of poster presentations at the 2008 ASCO meeting $(24,25)$. Cohen et al. (24) reported the best response rates as PR in 13\%, SD in $68 \%$, and PD in $10 \%$ of 37 patients with DTC (31 evaluable) after two completed cycles. In a second trial, 17 patients with advanced thyroid cancer (eight PTC, four MTC, one anaplastic thyroid cancer, and four other) were enrolled. Of 15 patients evaluable at 3 months, one had a PR and 12 patients had SD (25).

Apart from the multiple, ongoing, or completed clinical trials of TKIs in thyroid cancer, the US FDA and the European Medicines Agency have approved two TKIs for DTC. Sorafenib and lenvatinib are approved by the FDA for use in the context of PD that no longer responds to RAI treatment. The FDA approval was based on the results from two phase 3 clinical trials that showed significant improvement in PFS when compared to controls $(26,27)$. More specifically, lenvatinib prolonged PFS by almost 15 months (18.3 months vs 3.6 months; hazard ratio (HR) $0.21 ; P<0.001)$. Sorafenib significantly increased the median PFS in the treatment group when compared to the control group (10.8 months vs 5.8 months; HR 0.59; $P<0.0001)$. However, there is an imperative need to have available a variety of targeted therapies because of the diverse pathogenesis of advanced DTC. Our data demonstrate that sunitinib was effective against thyroid cancer, and this TKI could be further studied in that direction.

Despite the fact that TKIs have demonstrated a significant anti-neoplastic effect in studies performed in thyroid cancer, they do not represent a definitive form of therapy for the vast majority of patients. They are medications that can decelerate, or even halt, the progression of disease. However, the question that arises is what should be a feasible therapeutic option for patients that have failed a first-line TKI, such as sorafenib or lenvatinib. There is accumulating evidence that salvage therapy with a different TKI can be beneficial for patients that have already failed a first-line TKI (28). Salvage therapy TKIs can be effective even if they have a similar mechanism of action with the first-line agent. In that context, agents such as sunitinib may be extremely useful in the treatment of patients that have aggressive and/or progressive DTC.

The dosing and schedule used in our study was generally well-tolerated by the patients. The $37.5 \mathrm{mg} /$ once daily dose that we used was consistent with what some previous investigators have used (23), but different from the maximum dose of $50 \mathrm{mg}$ in a schedule $4 / 2$ schedule ( 4 weeks on therapy and 2-week rest) used in other studies $(24,25)$. We decided to use a continuous regimen of sunitinib to minimize the possibility for tumor escape during treatment and the lower dose of $37.5 \mathrm{mg}$ daily in order to compensate for the deletion of the rest period. The most common adverse events were either grade 1 or 2 , with hematologic toxicity (especially leukopenia), fatigue, and diarrhea being the most prevalent. However, the fact that sunitinib is a systemic therapy with a variety of offtarget effects is illustrated by the percentages of patients in whom discontinuation of treatment $(13 \%)$ or dose reduction (26\%) was required.

In summary, sunitinib in our study was well-tolerated and demonstrated significant anti-tumor activity in patients that had PD, despite having undergone at least one (and usually multiple) treatments with RAI. More studies in larger-scale cohorts are needed in order to clarify whether sunitinib can be used as a first-line TKI in those patients or should be used as a salvage therapy after patients' progression with one of the first-line agents.

\section{Supplementary data}

This is linked to the online version of the paper at http://dx.doi.org/10.1530/ EJE-15-0930.

\section{Declaration of interest}

The authors declare that there is no conflict of interest that could be perceived as prejudicing the impartiality of the research reported.

\section{Funding}

The study was supported by Pfizer, Inc. who provided the drug and administrative support, but had no involvement with data collection, analysis, and manuscript preparation.

\section{Acknowledgements}

The data from this study were presented in the $97^{\text {th }}$ Annual Meeting of the Endocrine Society (ENDO 2015) held in San Diego, CA.

\section{References}

1 SEER Stat Fact Sheets from http://seer.cancer.gov/statfacts/html/thyro. html accessed in 3/2015.

2 Cooper DS, Doherty GM, Haugen BR, Kloos RT, Lee SL, Mandel SJ, Mazzaferri EL, McIver B, Pacini F, Schlumberger M et al. Revised American Thyroid Association management guidelines for patients with thyroid nodules and differentiated thyroid cancer. Thyroid 2009 19 1167-1214. (doi:10.1089/thy.2009.0110) 
3 Sherman SI. Thyroid carcinoma. Lancet 2003361 501-511. (doi:10.1016/S0140-6736(03)12488-9)

4 Schlumberger MJ. Papillary and follicular thyroid carcinoma. New England Journal of Medicine 1998338 297-306. (doi:10.1056/ NEJM199801293380506)

5 Shoup M, Stojadinovic A, Nissan A, Ghossein RA, Freedman S, Brennan MF, Shah JP \& Shaha AR. Prognostic indicators of outcomes in patients with distant metastases from differentiated thyroid carcinoma. Journal of the American College of Surgeons 2003197 191-197. (doi:10.1016/S1072-7515(03)00332-6)

6 Huang IC, Chou FF, Liu RT, Tung SC, Chen JF, Kuo MC, Hsieh CJ \& Wang PW. Long-term outcomes of distant metastasis from differentiated thyroid carcinoma. Clinical Endocrinology 201276 439-447. (doi:10.1111/j.1365-2265.2011.04231.x)

7 Muresan MM, Olivier P, Leclère J, Sirveaux F, Brunaud L, Klein M, Zarnegar R \& Weryha G. Bone metastases from differentiated thyroid carcinoma. Endocrine-Related Cancer 200815 37-49. (doi:10.1677/ ERC-07-0229)

8 Durante C, Montesano T, Torlontano M, Attard M, Monzani F, Tumino S, Costante G, Meringolo D, Bruno R, Trulli F et al. Papillary thyroid cancer: time course of recurrences during postsurgery surveillance. Journal of Clinical Endocrinology and Metabolism 2013 98 636-642. (doi:10.1210/jc.2012-3401)

9 Samaan NA, Schultz PN, Hickey RC, Goepfert H, Haynie TP, Johnston DA \& Ordonez NG. The results of various modalities of treatment of well differentiated thyroid carcinomas: a retrospective review of 1599 patients. Journal of Clinical Endocrinology and Metabolism $199275714-720$.

10 Tuttle RM, Tala H, Shah J, Leboeuf R, Ghossein R, Gonen M, Brokhin M, Omry G, Fagin JA \& Shaha A. Estimating risk of recurrence in differentiated thyroid cancer after total thyroidectomy and radioactive iodine remnant ablation: using response to therapy variables to modify the initial risk estimates predicted by the new American Thyroid Association staging system. Thyroid 201020 1341-1349. (doi:10.1089/ thy.2010.0178)

11 Samaan NA, Maheshwari YK, Nader S, Hill CS Jr, Schultz PN, Haynie TP, Hickey RC, Clark RL, Goepfert H, Ibanez ML et al. Impact of therapy for differentiated carcinoma of the thyroid: an analysis of 706 cases. Journal of Clinical Endocrinology and Metabolism 198356 1131-1138. (doi:10.1210/jcem-56-6-1131)

12 Tubiana M, Schlumberger M, Rougier P, Laplanche A, Benhamou E, Gardet P, Caillou B, Travagli JP \& Parmentier C. Long-term results and prognostic factors in patients with differentiated thyroid carcinoma. Cancer 198555 794-804. (doi:10.1002/1097-0142(19850215)55:4 $<794:: A I D-C N C R 2820550418>3.0 . C O ; 2-Z)$

13 Ricarte-Filho JC, Ryder M, Chitale DA, Rivera M, Heguy A, Ladanyi M, Janakiraman M, Solit D, Knauf JA, Tuttle RM et al. Mutational profile of advanced primary and metastatic radioactive iodine-refractory thyroid cancers reveals distinct pathogenetic roles for BRAF, PIK3CA, and AKT1. Cancer Research 200969 4885-4893. (doi:10.1158/0008-5472. CAN-09-0727)

14 Durante C, Haddy N, Baudin E, Leboulleux S, Hartl D, Travagli JP, Caillou B, Ricard M, Lumbroso JD, De Vathaire F et al. Long-term outcome of 444 patients with distant metastases from papillary and follicular thyroid carcinoma: benefits and limits of radioiodine therapy. Journal of Clinical Endocrinology and Metabolism 200691 2892-2899. (doi:10.1210/jc.2005-2838)

15 Tuttle RM, Fleisher M, Francis GL \& Robbins RJ. Serum vascular endothelial growth factor levels are elevated in metastatic differentiated thyroid cancer but not increased by short-term TSH stimulation.
Journal of Clinical Endocrinology and Metabolism 200287 1737-1742. (doi:10.1210/jcem.87.4.8388)

16 Zhang J, Wang P, Dykstra M, Gelebart P, Williams D, Ingham R, Adewuyi EE, Lai R \& McMullen T. Platelet-derived growth factor receptor- $\alpha$ promotes lymphatic metastases in papillary thyroid cancer. Journal of Pathology 2012228 241-250. (doi:10.1002/path.4069)

17 Jhiang SM, Caruso DR, Gilmore E, Ishizaka Y, Tahira T, Nagao M, Chiu IM \& Mazzaferri EL. Detection of the PTC/retTPC oncogene in human thyroid cancers. Oncogene 19927 1331-1337.

18 Lam AK, Montone KT, Nolan KA \& Livolsi VA. Ret oncogene activation in papillary thyroid carcinoma: prevalence and implication on the histological parameters. Human Pathology 199829 565-568. (doi:10.1016/S0046-8177(98)80004-X)

19 Aparicio-Gallego G, Blanco M, Figueroa A, García-Campelo R, Valladares-Ayerbes M, Grande-Pulido E \& Antón-Aparicio L. New insights into molecular mechanisms of sunitinib-associated side effects. Molecular Cancer Therapeutics 201110 2215-2223. (doi:10.1158/ 1535-7163.MCT-10-1124)

20 Kim DW, Jo YS, Jung HS, Chung HK, Song JH, Park KC, Park SH, Hwang JH, Rha SY, Kweon GR et al. An orally administered multitarget tyrosine kinase inhibitor, SU11248, is a novel potent inhibitor of thyroid oncogenic RET/papillary thyroid cancer kinases. Journal of Clinical Endocrinology and Metabolism 200691 4070-4076. (doi:10.1210/jc.2005-2845)

21 Britten CD, Kabbinavar F, Hecht JR, Bello CL, Li J, Baum C \& Slamon D. A phase I and pharmacokinetic study of sunitinib administered daily for 2 weeks, followed by a 1-week off period. Cancer Chemotherapy and Pharmacology 200861 515-524. (doi:10.1007/s00280-007-0498-4)

22 Sweeney CJ, Chiorean EG, Verschraegen CF, Lee FC, Jones S, Royce M, Tye L, Liau KF, Bello A, Chao R et al. A phase I study of sunitinib plus capecitabine in patients with advanced solid tumors. Journal of Clinical Oncology 201028 4513-4520. (doi:10.1200/JCO.2009.26.9696)

23 Carr LL, Mankoff DA, Goulart BH, Eaton KD, Capell PT, Kell EM, Bauman JE \& Martins RG. Phase II study of daily sunitinib in FDG-PETpositive, iodine-refractory differentiated thyroid cancer and metastatic medullary carcinoma of the thyroid with functional imaging correlation. Clinical Cancer Research 201016 5260-5268. (doi:10.1158/1078-0432.CCR-10-0994)

24 Cohen EE, Needles BM, Cullen KJ, Wong SJ, Wade JL III, Ivy SP, Villaflor VM, Seiwert TY, Nichols K \& Vokes EE. Phase 2 study of sunitinib in refractory thyroid cancer. Journal of Clinical Oncology 2008 26S 6025 (abstract).

25 Ravaud A, de la Fouchardière C, Courbon F, Asselineau J, Klein M, Nicoli-Sire P, Bournaud C, Delord J, Weryha G \& Catargi B. Sunitinib in patients with refractory advanced thyroid cancer: the THYSU phase II trial. Journal of Clinical Oncology 2008 26S 6058 (abstract).

26 Brose MS, Nutting CM, Jarzab B, Elisei R, Siena S, Bastholt L, de la Fouchardiere C, Pacini F, Paschke R, Shong YK et al. Sorafenib in radioactive iodine-refractory, locally advanced or metastatic differentiated thyroid cancer: a randomised, double-blind, phase 3 trial. Lancet 2014384 319-328. (doi:10.1016/S0140-6736(14)60421-9)

27 Schlumberger M, Tahara M, Wirth LJ, Robinson B, Brose MS, Elisei R, Habra MA, Newbold K, Shah MH, Hoff AO et al. Lenvatinib versus placebo in radioiodine-refractory thyroid cancer. New England Journal of Medicine 2015372 621-630. (doi:10.1056/NEJMoa1406470)

28 Dadu R, Devine C, Hernandez M, Waguespack SG, Busaidy NL, Hu MI, Jimenez C, Habra MA, Sellin RV, Ying AK et al. Role of salvage targeted therapy in differentiated thyroid cancer patients who failed first-line sorafenib. Journal of Clinical Endocrinology and Metabolism 201499 2086-2094. (doi:10.1210/jc.2013-3588)

Received 17 September 2015

Revised version received 17 November 2015

Accepted 15 December 2015 